\title{
EFFECT OF SECONDARY ANNEALING PROCESS ON CRITICAL CURRENT DENSITY IN HIGHLY TEXTURED Bi-2212 SUPERCONDUCTING SYSTEM
}

\author{
M.A. AKSAN ${ }^{1}$, M.A. MADRE ${ }^{2}$, SH. RASEKH ${ }^{2}$, G. CONSTANTINESCU ${ }^{2}$,
} M.A. TORRES ${ }^{3}$, J.C. DIEZ ${ }^{2}$, A. SOTELO ${ }^{2}$ and M.E. YAKINCI ${ }^{1}$

${ }^{1}$ Inonu Universitesi, Fen Edebiyat Fakultesi, Fizik Bolumu 44280-Malatya, TURKEY

${ }^{2}$ ICMA (CSIC-Universidad de Zaragoza). María de Luna, 3. 50018-Zaragoza, SPAIN

${ }^{3}$ Universidad de Zaragoza, Dpto. de Ingeniería de Diseño y Fabricación. María de Luna 3, 50018-Zaragoza, SPAIN

Corresponding author: M.A. AKSAN

e-mail: mehmet.aksan@inonu.edu.tr

Address: Inonu Universitesi, Fen Edebiyat Fakultesi, Fizik Bolumu 44280-Malatya, Turkey Tel: +904223773720

Fax: +90 4223410319 


\section{Abstract}

Bi-2212 samples prepared by a solid-state reaction technique have been grown from the melt using the laser floating zone method. After annealing the as-grown bars, the samples showed a good grain alignment and a high transport critical current density. Secondary annealing processes were performed on the annealed samples with the aim of producing Bi2212 phase controlled decomposition. Hence, the Bi-2201 phase and the secondary phases which act as effective pinning centers, were obtained with the secondary annealing process. After these thermal treatments, the transport critical current densities of samples significantly increased, when compared to the annealed ones. The maximum critical current density was achieved when the samples were subjected to secondary annealing at $680{ }^{\circ} \mathrm{C}$ for $168 \mathrm{~h}$ with an improvement of $\sim 80 \%$, compared to the annealed ones. Moreover, it was found that magnetization of the secondarily annealed samples was also increased. The magnetic critical current densities in these secondary annealed samples were about 3 times higher than the values obtained for the annealed ones. These results clearly indicate that the secondary annealing processes lead to the formation of effective pinning centers in the bulk material.

PACS: $74.72 .-\mathrm{h} ;$ 74.25.Ha; 74.25.Sv

Keywords: BSCCO Cuprates; Magnetic properties; Critical current density 


\section{INTRODUCTION}

Since the discovery of the high-temperature $\left(\mathrm{HT}_{c}\right) \mathrm{BiSrCaCuO}$ (BSCCO) superconducting system [1], many studies have been made to improve its superconducting properties. Some of these studies have been related with synthesis processes [2-5], cationic substitutions, as $\mathrm{Pb}^{2+}$ for $\mathrm{Bi}^{3+}[6,7]$ or transition metals for $\mathrm{Cu}[8,9]$, and compositional modifications [10,11]. In spite of these intense works, weak-links and grains random orientation are still important drawbacks in these materials, which avoid reaching high superconducting transport properties.

Fabrication of textured $\mathrm{HT}_{c}$ superconducting materials with high electrical and magnetic properties is necessary for practical applications at $77 \mathrm{~K}$ [12]. $\mathrm{HT}_{c} \mathrm{BSCCO}$ system possesses a very important crystallographic anisotropy which is reflected in a preferential grain growth along the $a b$-planes which are the conducting ones. As a consequence, the alignment of $a b$-planes, results in the reduction of number of low-angle grain boundaries, maximizing the transport properties. As a consequence, these alignment processes are essential for technological applications needing high transport properties [13]. Different conformation methods have been successfully used to produce well oriented grains with their $a b$-planes parallel to the current flow, such as sinter-forging [14], partial melting [15] or directional solidification from a totally molten material [16-19]. Among all these methods, the laser floating zone (LFZ) method has been shown as very suitable to produce textured materials with high electrical and magnetic properties at a relatively high growth rates [2022]. On the other hand, it should be considered that BSCCO system shows incongruent melting producing several secondary phases. As a consequence, after the growth process it is 
necessary to perform an annealing treatment in order to recombine the secondary phases formed in the texturing process to produce the superconducting one [23].

Flux pinning is a well known phenomenon which, in spite of the Lorentz force, avoids the movement of magnetic flux lines in a current-carrying type-II superconductor. The motion of vortices in type-II superconductors and, in particular, in high-Tc superconducting (HTSC) cuprates is avoided by pinning forces associated with different structural defects, such as edge dislocations, twin planes, and grain boundaries as well as by artificial, radiation-induced columnar defects $[24,25]$. Flux pinning is a desirable phenomenon in high temperature ceramic superconductors in order to prevent flux creep, which can create a pseudo-resistance and depress both critical current density and critical field. In the BSCCO system, the Bi-O layers between the superconducting $\mathrm{CuO}$ planes limit carrier conduction between planes, leading to a weak vortex coupling. The magnetic vortices are usually represented as $2 \mathrm{D}$ flat disks, called pancakes [26], which can be pinned by insulating and small size secondary phases. As a consequence, pinning centers lead to improvements in the critical current density, $J_{c}$. Due to these factors, many works have been performed on the production of effective pinning centers in this system. The first approach is the chemical substitution and/or addition of foreign compounds to create pinning centers in the system [27-30]. The second one is the formation of effective pinning centers by a temperature-controlled decomposition of the superconducting phase, producing insulating phases with sizes depending on the thermal treatment duration [31-34].

The aim of this work is developing a simple process to produce effective pinning centers by the controlled decomposition of the superconducting $\mathrm{Bi}_{2} \mathrm{Sr}_{2} \mathrm{CaCu}_{2} \mathrm{O}_{8+\delta}(\mathrm{Bi}-2212)$ phase by secondary annealing treatments using different temperatures and durations. The optimal processes should raise the transport and magnetic $J_{c}$ of LFZ-grown Bi-2212 superconducting samples without a drastic microstructural modification. 


\section{EXPERIMENTAL DETAILS}

Bi-2212 samples with $\mathrm{Bi}_{2} \mathrm{Sr}_{2.1} \mathrm{Ca}_{0.9} \mathrm{Cu}_{2} \mathrm{O}_{8+\delta}$ nominal composition were prepared by the conventional solid-state reaction technique. $\mathrm{Bi}_{2} \mathrm{O}_{3}\left(98 \%\right.$, Panreac), $\mathrm{SrCO}_{3}(98+\%$, Panreac), $\mathrm{CaCO}_{3}(98.5 \%$, Panreac), and $\mathrm{CuO}(98 \%$, Panreac) commercial powders were weighed in the appropriate proportions and ball-milled in a planetary ball-mill using acetone media for 30 min at $300 \mathrm{rpm}$. The obtained suspension was subsequently dried in an infrared (IR)-operated quick dryer system. The dried mixture was manually milled to break agglomerates produced in the drying procedure. The homogeneous powder mixture was heat treated twice at 750 and $800{ }^{\circ} \mathrm{C}$ for $12 \mathrm{~h}$ under air, with an intermediate manual milling, to assure the complete decomposition of alkaline-earth carbonates [35]. The resulting powders were then isostatically cold pressed at $\sim 200 \mathrm{MPa}$ to obtain green ceramic cylinders which were subsequently used as feed in a LFZ device equipped with a continuous power Nd:YAG laser $(\lambda=1.06 \mu \mathrm{m})$ described elsewhere [36]. The LFZ process was performed in the same conditions for all the samples; they were directionally solidified from the melt at $30 \mathrm{~mm} / \mathrm{h}$ with a seed rotation of 3 rpm to maintain the cylindrical geometry. Moreover, an opposite feed rotation of $15 \mathrm{rpm}$ was applied to assure compositional homogeneity in the molten zone. Finally, after the texturing process, long (more than $15 \mathrm{~cm})$ and geometrically homogeneous $(\sim 2 \mathrm{~mm}$ diameter) textured cylindrical rods were produced.

As mentioned previously, the $\mathrm{Bi}-2212$ phase presents incongruent melting producing $\mathrm{Bi}_{2} \mathrm{Sr}_{2} \mathrm{CuO}_{\mathrm{x}}(\mathrm{Bi}-2201)$ and cuprate phases, in agreement with the equilibrium phase diagram [31]. Consequently, after the directional solidification process it is necessary to perform a heat treatment to produce the Bi-2212 phase from the secondary ones [37,38]. This annealing process is performed under air and consists in two steps: First heat treatment at $860{ }^{\circ} \mathrm{C}$ for 60 
$\mathrm{h}$ to produce the $\mathrm{Bi}-2212$ phase, and second one at $800{ }^{\circ} \mathrm{C}$ for $12 \mathrm{~h}$ to adjust the oxygen content in the superconducting phase, followed by quenching in air to room temperature. On the other hand, before the heat treatment procedure, as-grown samples were cut into pieces for the electrical transport measurements $(\sim 3 \mathrm{~cm}$ long) and four-point probe contacts were painted on these pieces using Ag paste. After thermal treatment, typical resistance values of these contacts are below $1 \mu \Omega$ [39]. Moreover, for the magnetic measurements, smaller pieces $(\sim 0.5 \mathrm{~cm}$ long) were cut from as-grown bars and directly subjected to the thermal treatment process. After these annealing processes, some of the samples were kept to be used as reference, while others were subjected to secondary annealing treatments. Two different temperatures and time scales were used: $680{ }^{\circ} \mathrm{C}$ between 24 and $312 \mathrm{~h}$ and $900{ }^{\circ} \mathrm{C}$ between 1 and $4 \mathrm{~min}$. Difference among the chosen heat secondary annealing durations is due to the different decomposition rates induced by these two temperatures.

Structural evaluation of the samples, before and after the secondary annealing processes, was carried out using X-ray powder diffraction measurements (Rigaku D/max-B) between 10 and $60^{\circ}$. Microstructural characterizations were performed on polished longitudinal sections of the samples in a field emission scanning electron microscope (FESEM, Carl Zeiss MERLIN) equipped with an energy dispersive spectroscopy (EDX) system.

Electrical measurements were performed by the conventional four-point probe technique. Resistivity as a function of temperature from 77 to $300 \mathrm{~K}$ was measured using a dc current of $1 \mathrm{~mA}$. Transport critical current intensity ( $\left.I_{c}^{\text {trans }}\right)$ was determined from the I-V curves at $77 \mathrm{~K}$, using the $1 \mu \mathrm{V} / \mathrm{cm}$ standard criterion. From the I-V data, the transport critical current density $\left(J_{c}^{\text {trans }}\right)$ values were calculated with the samples dimensions. The magnetic properties of the samples were studied using a Quantum Design Physical Properties 
Measurement System (PPMS-9T). Temperature dependence of magnetization was measured under an applied magnetic field of 50 Oe perpendicular to the growth direction. $\mathrm{M}-\mathrm{H}$ measurements were carried out under external magnetic fields up to $9 \mathrm{~T}$ at three different temperatures $(5,15$ and $25 \mathrm{~K})$. From M-H hysteresis loops, the magnetic critical current density, $J_{c}^{\text {mag }}$, was calculated using Beans' equation [40].

\section{RESULTS AND DISCUSSION}

Figure 1 shows the XRD patterns of samples subjected to different thermal treatments. The peaks corresponding to the $\mathrm{Bi}-2212$ phase have been indexed in the figure, in agreement with previously published data [5]. In these patterns, it has been found that the annealed samples are nearly pure Bi-2212. Moreover, it can be observed that no evident modifications are produced after the secondary annealing processes, independently of temperature and heat treatment duration. From these observations, it can be deduced that the secondary annealing processes caused only the decomposition of a very small amount of $\mathrm{Bi}-2212$ phase, leading to very small proportions of secondary phases with very small sizes, avoiding their detection by XRD analyses.

Figure 2 shows SEM images performed on polished longitudinal sections of samples with different thermal treatments. In the annealed samples, three different contrasts were identified and numbered, for clarity, in the corresponding micrograph. EDX analysis revealed that these contrasts corresponded to Bi-2212 (\#1, grey contrast) as the major phase, and Bi2201 (\#2, light grey contrast), and $(\mathrm{Sr}, \mathrm{Ca}) \mathrm{CuO}_{2}(\# 3$, dark grey contrast) as minor secondary ones. When these samples were subjected to the different secondary annealing treatments, the Bi-2212 phase is decomposed, producing secondary phases, as it can be observed in the phase 
equilibrium diagram [31]. From this diagram, it can be deduced that the samples treated at $680{ }^{\circ} \mathrm{C}$ should possess $\mathrm{Bi}_{2+\mathrm{x}}(\mathrm{Sr}, \mathrm{Ca})_{2} \mathrm{CuO}_{6+\delta}, \mathrm{Sr}_{3} \mathrm{Bi}_{2} \mathrm{O}_{6}$, and $\mathrm{Sr}_{14} \mathrm{Cu}_{24} \mathrm{O}_{41-\mathrm{x}}$ phases in different amounts and sizes, depending on the thermal treatment duration. In the corresponding micrographs it can be observed that Bi-2212 is still the major phase (grey contrast, \#1). Additionally, three different contrasts were also identified in these images and EDX has determined their composition as $\mathrm{Bi}_{2+\mathrm{x}}(\mathrm{Sr}, \mathrm{Ca})_{2} \mathrm{CuO}_{6+\delta}$ (\#4, light grey), $\mathrm{Sr}_{3} \mathrm{Bi}_{2} \mathrm{O}_{6}$ (\#5, white) and $\mathrm{Sr}_{14} \mathrm{Cu}_{24} \mathrm{O}_{41-\mathrm{x}}$ (\#6, dark grey). On the other hand, as it is difficult to distinguish between white and light grey contrasts in the micrographs, an inset in the figure shows the white contrast (\#5). As can be observed in the inset, the white phase is appearing as very fine linear grains between the $\mathrm{Bi}-2212$ grains and close to the regions where the $\mathrm{Sr}_{14} \mathrm{Cu}_{24} \mathrm{O}_{41-\mathrm{x}}$ phase appears. All these results agree with the previously ones obtained in similar works $[31,34]$.

When the samples are thermally treated at $900{ }^{\circ} \mathrm{C}$, the phase decomposition is much quicker due to the formation of a liquid phase, in agreement with the phase equilibrium diagram [31]. In this case, Bi-2212 phase is still the major one (grey contrast, \#1). Moreover, some secondary phases are appearing, as $\mathrm{Bi}_{2+\mathrm{x}}(\mathrm{Sr}, \mathrm{Ca})_{2} \mathrm{CuO}_{6+\delta}$ (light grey contrast, \#4) and $(\mathrm{Sr}, \mathrm{Ca}) \mathrm{Cu}_{2} \mathrm{O}_{3}$ solid solution with different $\mathrm{Ca}$ and $\mathrm{Sr}$ proportions between regions (black contrast, \#7). These phases are in accordance with the expected ones from the previously mentioned phase equilibrium diagram [31] and with the observed in previous works in this system [34].

Electrical resistivity variation with temperature for the annealed and secondarily annealed samples is presented in Figure 3. As it can be easily observed in the plot, all the samples show metallic behavior from room temperature down to $T_{c}$. Zero resistivity temperature, $T_{0}$, values do not significantly change with the different thermal treatments. $T_{0}$ values for the annealed samples were $\sim 90 \mathrm{~K}$, however $T_{0}$ values for the secondarily annealed 
samples at $680{ }^{\circ} \mathrm{C}$ for 24 and $312 \mathrm{~h}$ were 88 and $87 \mathrm{~K}$ while they were 89 and $90.5 \mathrm{~K}$ for the samples heat treated at $900{ }^{\circ} \mathrm{C}$ for 2 and $4 \mathrm{~min}$, respectively. These results clearly indicate that the samples consist of nearly pure Bi-2212 and that the secondary annealing treatments slightly change the $T_{0}$ values. From these data, it can be deduced that the conducting path is only slightly affected by the secondary annealing treatments. On the other hand, normal state resistivity values are, approximately, the same at $300 \mathrm{~K}$ for the annealed samples and those thermally treated at $680{ }^{\circ} \mathrm{C}$ for $168 \mathrm{~h}$. Samples treated for longer times raise the normal state resistivity value at $300 \mathrm{~K}$, compared with the annealed ones. This is a clear indication of Bi2212 decomposition, raising the amount of secondary phases. Furthermore, the normal state resistivity at $300 \mathrm{~K}$ is still raised in samples heated at $900{ }^{\circ} \mathrm{C}$, showing that the decomposition process of $\mathrm{Bi}-2212$ phase is speeded up, compared with the other samples, due to the liquid phase formation discussed previously.

Transport critical current intensity, $I_{c}^{\text {trans }}$, determined from I-V characteristics, and samples dimensions, allowed calculating transport critical current density, $J_{c}^{\text {trans }}$, which is plotted in Figure 4 as a function of the secondary annealing durations. It is obvious that these thermal treatment processes lead to an important increase in $J_{c}^{\text {trans }}$. The maximum $J_{c}^{\text {trans }}$ value $\left(3650 \mathrm{~A} / \mathrm{cm}^{2}\right)$ was obtained in samples subjected to secondary annealing at $680{ }^{\circ} \mathrm{C}$ for $164 \mathrm{~h}$. In the case of samples treated at $900{ }^{\circ} \mathrm{C}$, the maximum values reach only $2750 \mathrm{~A} / \mathrm{cm}^{2}$ after 2 min. These $J_{c}^{\text {trans }}$ values are much higher ( 75 and $30 \%$, respectively) than the value obtained in the annealed samples $\left(\sim 2050 \mathrm{~A} / \mathrm{cm}^{2}\right)$. On the other hand, $J_{c}^{\text {trans }}$ is strongly decreased for longer secondary annealing durations, independently of the temperature. These results clearly point out that the secondary annealing process can produce a beneficial effect on the transport properties of the Bi-2212 textured samples when it is adequately controlled. 
Magnetic behavior of samples as a function of temperature under an applied field of 50 Oe, is illustrated in Figure 5. The diamagnetic signal started at approximately the same temperatures in all samples. Moreover, the transition between normal and superconducting state is sharp in all cases, indicating that the individual grains can shield the magnetic field. As it can be observed, the diamagnetic signal is raised in all secondarily annealed samples, probably due to changes in their density, compared with the annealed ones. Furthermore, the strong increase of diamagnetic signal observed thermally treated samples at $680{ }^{\circ} \mathrm{C}$ for $168 \mathrm{~h}$ can be due to these density modifications, together with changes in their demagnetization factor. The diamagnetic onset temperature, $T_{c}^{\text {mag }}$, of samples is ranging from $68.75 \mathrm{~K}$ for the annealed samples to $74.66 \mathrm{~K}$ for the secondarily annealed samples at $680{ }^{\circ} \mathrm{C}$ for $312 \mathrm{~h}$ and $75.11 \mathrm{~K}$ for the samples treated at $900{ }^{\circ} \mathrm{C}$ for $4 \mathrm{~min}$. As a consequence, it is possible to establish that the microstructural changes induced by these additional thermal treatments do not induce drastic modifications on the $T_{c}^{\text {mag }}$ values.

The $\mathrm{M}-\mathrm{H}$ curves determined at 5 and $25 \mathrm{~K}$ for some of the samples are presented in Figure 6. The other samples (not drawn for clarity) displayed similar M-H trends. As it can be seen in the graphs, the shape of the M-H loops changed when the measurement temperature was increased from $5 \mathrm{~K}$ to $25 \mathrm{~K}$. The magnetization decreased when the temperature and the applied magnetic field are increased, which can be attributed to the flux motion. At low temperatures, the flux pinning is strong and fluxes mostly penetrate the crystals as vortices. Vortex motion begins with the increase of temperature, which leads to a deterioration of fluxes magnetic configuration. It should be highlighted that the magnetization is higher in the secondarily annealed samples at $680{ }^{\circ} \mathrm{C}$ than in the ones thermally treated at $900{ }^{\circ} \mathrm{C}$, independently of the measuring temperature. This effect can be associated with the secondary phases produced by these additional thermal treatments. It could be expected that the produced secondary phases can act as effective pinning centers due to their nature and sizes. 
As a consequence, an increase in the magnetization has been found until $168 \mathrm{~h}$ thermal treatment. Longer secondary annealing increases the size of these secondary phases, decreasing their effectiveness and deteriorating the magnetic behavior of samples. The same reasoning can be applied to the magnetic behavior observed for the secondarily annealed samples at $900{ }^{\circ} \mathrm{C}$. However, these high temperatures promote a quicker Bi-2212 phase decomposition and higher growth rate of the secondary phases due to the already mentioned effect of liquid phase formation.

$J_{c}^{\text {Mag }}$ of all samples was calculated using Beans' equation [40]:

$$
J_{c}^{\text {mag }}=\frac{30 \Delta M}{d}
$$

where $\Delta M$ is the width of the magnetization hysteresis, and $d$ the diameter of the cylindrical samples. The magnetic field dependence of $J_{c}^{\text {Mag }}$ as a function of the measurement temperature is shown in Figure 7. At a first sight, it is clear that $J_{c}^{M a g}-\mathrm{H}$ behavior is very similar for all the samples. Secondarily annealed samples show $J_{c}^{\text {Mag }}$ higher than the obtained in annealed ones. On the other hand, the thermally treated samples at $680{ }^{\circ} \mathrm{C}$ showed higher $J_{c}^{\text {Mag }}$ values than the obtained for the ones treated at $900{ }^{\circ} \mathrm{C}$. The $J_{c}^{\text {Mag }}$ values for the annealed samples were $2.25 \times 10^{5} \mathrm{~A} / \mathrm{cm}^{2}$ while the maximum ones for the secondarily annealed samples were obtained for the ones thermally treated at 680 for $168 \mathrm{~h}$ and $900{ }^{\circ} \mathrm{C}$ for $2 \mathrm{~min}$ (around $6.55 \times 10^{5}$ and $4.50 \times 10^{5} \mathrm{~A} / \mathrm{cm}^{2}$, respectively). As a consequence, secondarily annealed samples exhibited $J_{c}^{\text {Mag }}$ values about 3 and 2 times higher, respectively, than the obtained in annealed 
ones. The increase in $J_{c}^{\text {Mag }}$ can be associated to the formation of non-superconducting secondary phases such as $\mathrm{Sr}_{3} \mathrm{Bi}_{2} \mathrm{O}_{6}$ or $\mathrm{Sr}_{14} \mathrm{Cu}_{24} \mathrm{O}_{41-\mathrm{x}}$ produced during the $\mathrm{Bi}-2212$ phase decomposition in the secondary annealing conditions. These phases, detected in the SEM investigations, can act as effective pinning centers due to their isolating nature and sizes, raising the magnetic response of secondarily annealed samples leading to higher $J_{c}^{\text {Mag }}$ values than the measured in annealed ones.

\section{CONCLUSIONS}

Well textured $\mathrm{Bi}_{2} \mathrm{Sr}_{2.1} \mathrm{Ca}_{0.9} \mathrm{Cu}_{2} \mathrm{O}_{8+\delta}$ samples were successfully grown from the melt using the LFZ process. After the annealing process, nearly pure superconducting Bi-2212 phase has been obtained. Secondary annealing processes performed on the annealed samples caused an enhancement in the electrical and magnetic properties of samples. This enhancement can be explained by the controlled thermal decomposition of the Bi-2212 phase during the secondary annealing processes. These decomposition processes led to the formation of small and well distributed isolating secondary phases which can act as effective pinning centers. It has been found that these decomposition processes are very quick at high temperatures $\left(900{ }^{\circ} \mathrm{C}\right)$ while it is slower at low ones $\left(680^{\circ} \mathrm{C}\right)$. Microstructural studies have also demonstrated that these decomposition processes produce the secondary phases predicted in the phase equilibrium diagram. Transport and magnetic measurements have shown that secondary annealing raises the samples performances. Moreover, the improvements become more important when the samples are thermally treated at low temperatures. The best results have been obtained in samples subjected to a secondary annealing at $680{ }^{\circ} \mathrm{C}$ for $168 \mathrm{~h}$ which 
drastically improves $J_{c}^{\text {trans }}$ and $J_{c}^{\text {Mag }}$ values in about 80 and $300 \%$, compared with the values measured in the annealed ones. All these results clearly indicate that it is possible to produce effective pinning centers with the adequate sizes and isolating nature by careful control of the Bi-2212 phase decomposition processes.

\section{ACKNOWLEDGEMENTS}

The authors acknowledge financial support from the Gobierno de Aragón (Grupos de Investigacion Consolidados T12 and T87) and the Spanish MINECO-FEDER (Project MAT2013-46505-C3-1-R). The technical contributions of C. Estepa and C. Gallego are also acknowledged.

\section{REFERENCES}

[1] H.Maeda, Y. Tanaka, M. Fukutomi and T. Asano, Jpn. J. Appl. Phys., 27, L209-L210 (1988)

[2] G. F. de la Fuente, A. Sotelo, Y. Huang, M. T. Ruiz, A. Badia, L. A. Angurel, F. Lera, R. Navarro, C. Rillo, R. Ibañez, D. Beltran, F. Sapiña and A. Beltran, Physica C, 185, 509-510 (1991).

[3] A. Sotelo, P. Majewski, H. S. Park and F. Aldinger, Physica C, 272, 115-124 (1996).

[4] V. Rouessac, J. Wang, J. Provost and G. Desgardin, J. Mater. Sci., 31, 3387-3390 (1996).

[5] A. Sotelo, H. Szillat, P. Majewski and F. Aldinger, Supercond. Sci. Technol., 10, 717- 
720 (1997).

[6] A. Sotelo, M. Mora, M. A. Madre, H. Amaveda, J. C. Diez, L. A. Angurel and M. Mayoral, Bol. Soc. Esp. Ceram. V., 45, 228-232 (2006).

[7] L. Shi, Q. Dong and Y. Zhang, Physica C, 341, 649-650 (2000).

[8] B. Ozkurt, M. A. Madre, A. Sotelo and J. C. Diez, J. Mater Sci-Mater. Electron., 24, 1158-1167 (2013).

[9] M. Ozabaci, A. Sotelo, M. A. Madre and M. E. Yakinci, J. Supercond. Nov. Magn., 26, 1143-1149 (2013).

[10] A. Sotelo, L. A. Angurel, M. T. Ruiz, A. Larrea, F. Lera and G. F. de la Fuente, Solid State Ionics, 63-65, 883-888 (1993).

[11] M. F. Carrasco, R. A. Silva, R. F. Silva, V. S. Amaral and F. M. Costa, Physica C, 460-462, 1347-1348 (2007).

[12] M. Chen, L. Donzel, M. Lakner and W. Paul, J. Eur. Ceram. Soc., 24, 1815-1822 (2004).

[13] D. Shi, in High Temperature Superconducting Materials Science and Engineering, ed. D. Shi (Oxford: Pergamon Press, 1995).

[14] V. Garnier, R. Caillard, A. Sotelo and G. Desgardin, Physica C, 319, 197-208 (1999).

[15] S. Marinel, D. Bourgault, O. Belmont, A. Sotelo and G. Desgardin, Physica C, 315, 205-214 (1999).

[16] Y. Huang, G.F. de la Fuente, A. Sotelo, A. Badia, F. Lera, R. Navarro, C. Rillo, R. Ibañez, D. Beltran, F. Sapiña and A. Beltran, Physica C, 185-189, 2401-2402 (1991).

[17] M.F. Carrasco, F.M. Costa, R.F. Silva, F. Gimeno, A. Sotelo, M. Mora, J.C. Diez and L.A. Angurel, Physica C, 415, 163-171 (2004).

[18] J. M. Vieira, R. A. Silva, R. F. Silva and F. M. Costa, Appl. Surf. Sci., 258, 9175$9180(2012)$. 
[19] F. M. Costa, N. M. Ferreira, Sh. Rasekh, A. J. S. Fernandes, M. A. Torres, M. A. Madre, J. C. Diez and A. Sotelo, Crystal Growth Design, 15, 2094-2101 (2015).

[20] M. Mora, A. Sotelo, H. Amaveda, M. A. Madre, J. C. Diez, F. Capel and J. M. LopezCepero, J. Eur. Ceram. Soc., 27, 3959-3962 (2007).

[21] A. Sotelo, Sh. Rasekh, M. A. Madre and J. C. Diez, J. Supercond. Nov. Magn., 24, $19-25(2011)$.

[22] G. F. de la Fuente, M. T. Ruiz, A. Sotelo, A. Larrea and R. Navarro, Mat. Sci. Eng. A, 173, 201-204 (1993).

[23] M. Mora, A. Sotelo, H. Amaveda, M. A. Madre, J. C. Diez, L. A. Angurel and G. F. de la Fuente, Bol. Soc. Esp. Ceram. V., 44, 199-203 (2005).

[24] J. M. Huijbregtse, B. Dam, R. C. F. van der Geest, F. C. Klaassen, R. Elberse, J. H.Rector, and R. Griessen, Phys. Rev. B, 62, 1338--1349 (2000).

[25] J. Albrecht, Phys. Rev. B, 68, 054508 (2003).

[26] J.R. Clem, J. Supercond. Incorp. Novel Magn., 17, 613-629 (2004).

[27] M. Anis-ur-Rehman and M. Mubeen, Synthetic Met., 162, 1769-1774 (2012).

[28] J. De Vero, G. Blanca, J. Vitug, W. Garcia and R. Sarmago, Physica C, 471, 378-383 (2011).

[29] J. Kumar, D. Sharma, P.K. Ahluwalia and V.P.S. Awana, Mater. Chem. Phys., 139, $681-688(2013)$.

[30] N. Ghazanfari, A. Kılıc, A. Gencer and H. Ozkan, Solid State Commun., 144, 210-214 (2007).

[31] P. Majewski, S. Elschner and F. Aldinger, Physica C, 249, 234-240 (1995).

[32] P. Majewski, H.-L. Su and F. Aldinger, J. Mater. Sci., 31, 2035-2042 (1996).

[33] T.-M. Qu, Z. Han and R. Flukiger, Physica C, 444, 71-76 (2006).

[34] A. Sotelo, M. A. Madre, Sh. Rasekh, G. Constantinescu, M. A. Torres and J. C. Diez, 
J. Supercond. Nov. Magn., 26, 985-990 (2013).

[35] M. A. Madre, H. Amaveda, M. Mora, A. Sotelo, L. A. Angurel and J. C. Diez, Bol. Soc. Esp. Ceram. V., 47, 148-152 (2008).

[36] Sh. Rasekh, N. M. Ferreira, F. M. Costa, G. Constantinescu, M. A. Madre, M. A. Torres, J. C. Diez and A. Sotelo, Scripta Mater., 80, 1-4 (2014).

[37] R. Funahashi, I. Matsubara, K. Ueno and H. Ishikawa, Physica C, 311, 107-121 (1999).

[38] B. Ozkurt, M. A. Madre, A. Sotelo, M. E. Yakinci and B. Ozcelik, J. Supercond. Nov. Magn., 25, 799-804 (2012).

[39] L. A. Angurel, J. C. Diez, G. F. de la Fuente, F. Gimeno, F. Lera, C. Lopez-Gascon, E. Martinez, M. Mora, R. Navarro, A. Sotelo, N. Andres, S. Recuero and M. P. Arroyo, Phys. Status Solidi A, 203, 2931-2937, (2006).

[40] C. P. Bean, Phys. Rev. Lett., 8, 250-253 (1962). 


\section{Figure Captions}

Figure 1. XRD patterns of textured Bi-2212 samples with the different thermal treatments. The Bi-2212 diffraction peaks have been identified by the corresponding crystallographic planes.

Figure 2. Representative SEM images performed on polished longitudinal sections of textured Bi-2212 samples with different thermal treatments. Inset is a high magnification micrograph to clearly show the $\mathrm{Sr}_{3} \mathrm{Bi}_{2} \mathrm{O}_{6}$ secondary phase. The numbers indicate the different phases: 1) $\mathrm{Bi}-2212$; 2) $\mathrm{Bi}-2201 ; 3)(\mathrm{Sr}, \mathrm{Ca}) \mathrm{CuO}_{2}$; 4) $\left.\left.\mathrm{Bi}_{2+x}(\mathrm{Sr}, \mathrm{Ca})_{2} \mathrm{CuO}_{6+\delta} ; 5\right) \mathrm{Sr}_{3} \mathrm{Bi}_{2} \mathrm{O}_{6} ; 6\right)$ $\mathrm{Sr}_{14} \mathrm{Cu}_{24} \mathrm{O}_{41-\mathrm{x}}$; and 7) $(\mathrm{Sr}, \mathrm{Ca}) \mathrm{Cu}_{2} \mathrm{O}_{3}$.

Figure 3. Electrical resistivity evolution with temperature determined for textured Bi-2212 samples subjected to different thermal treatments.

Figure 4. $\mathrm{J}_{\mathrm{c}}$ values as a function of the secondary annealing duration in textured samples treated at different temperatures.

Figure 5. Magnetization curves as a function of measuring temperature determined in textured Bi-2212 samples with different thermal treatments. 
Figure 6. Hysteresis loops obtained at different temperatures for textured samples subjected to different thermal treatments.

Figure 7. $J_{c}^{\text {Mag }}$ vs. magnetic applied field, as a function of the measurement temperature for annealed (a) and secondarily annealed samples at 680 (b) and $900{ }^{\circ} \mathrm{C}$ (c). 
Figure 1

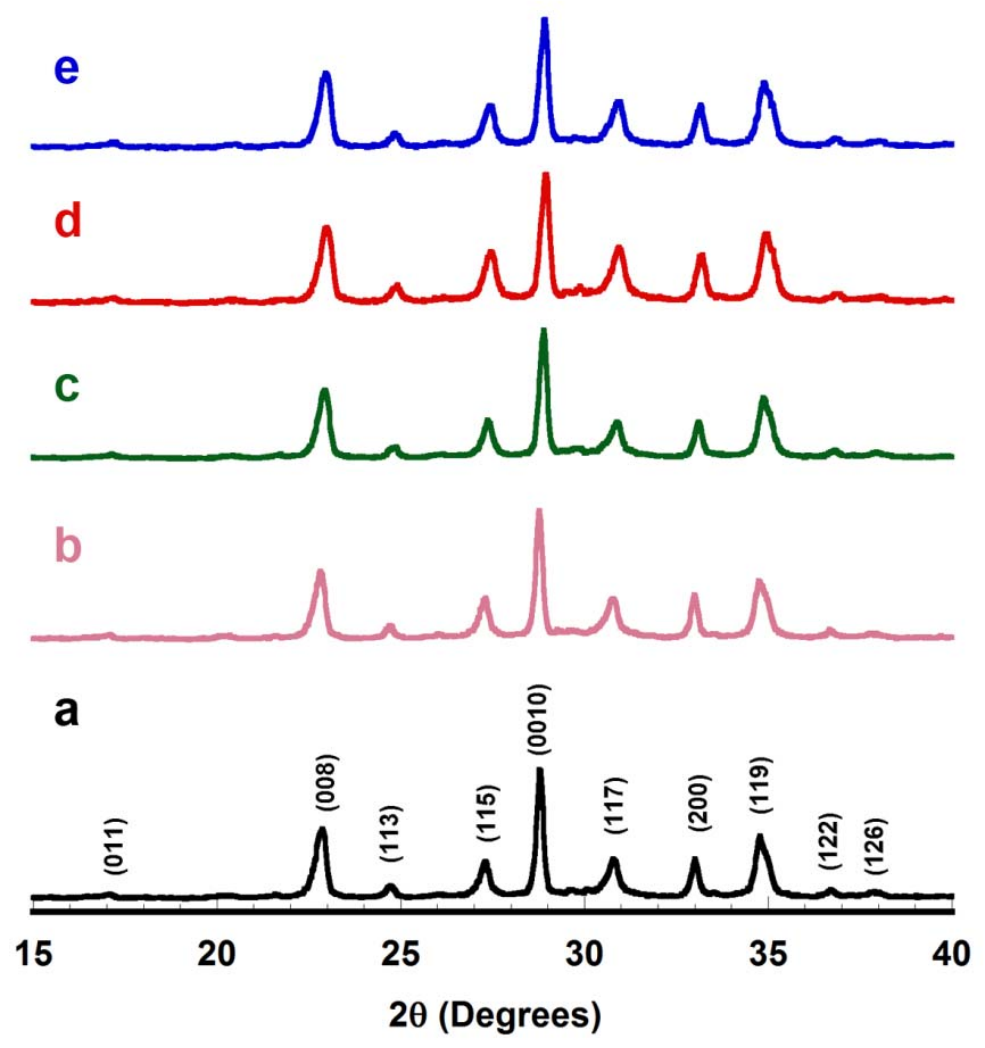


Figure 2

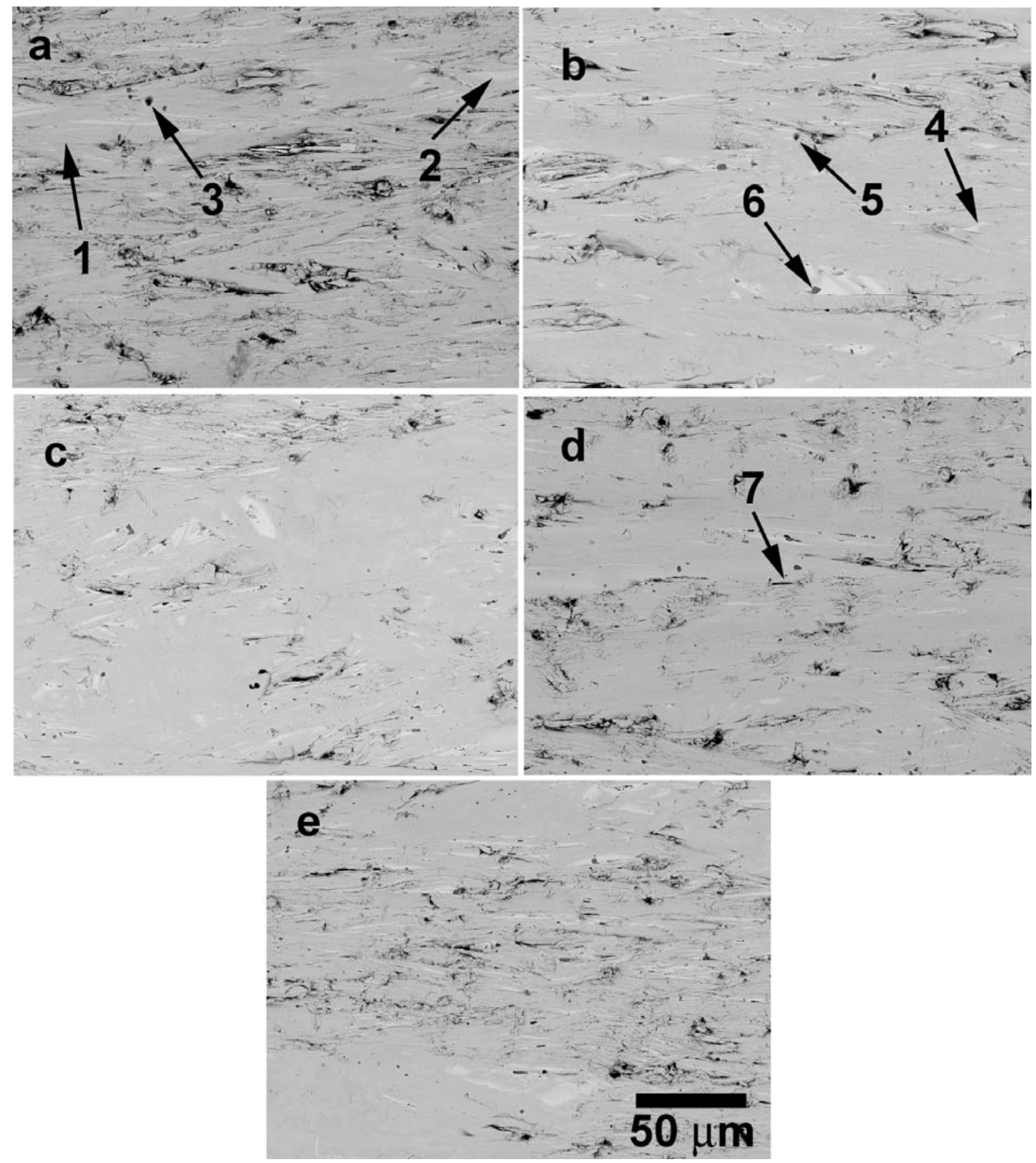


Figure 3

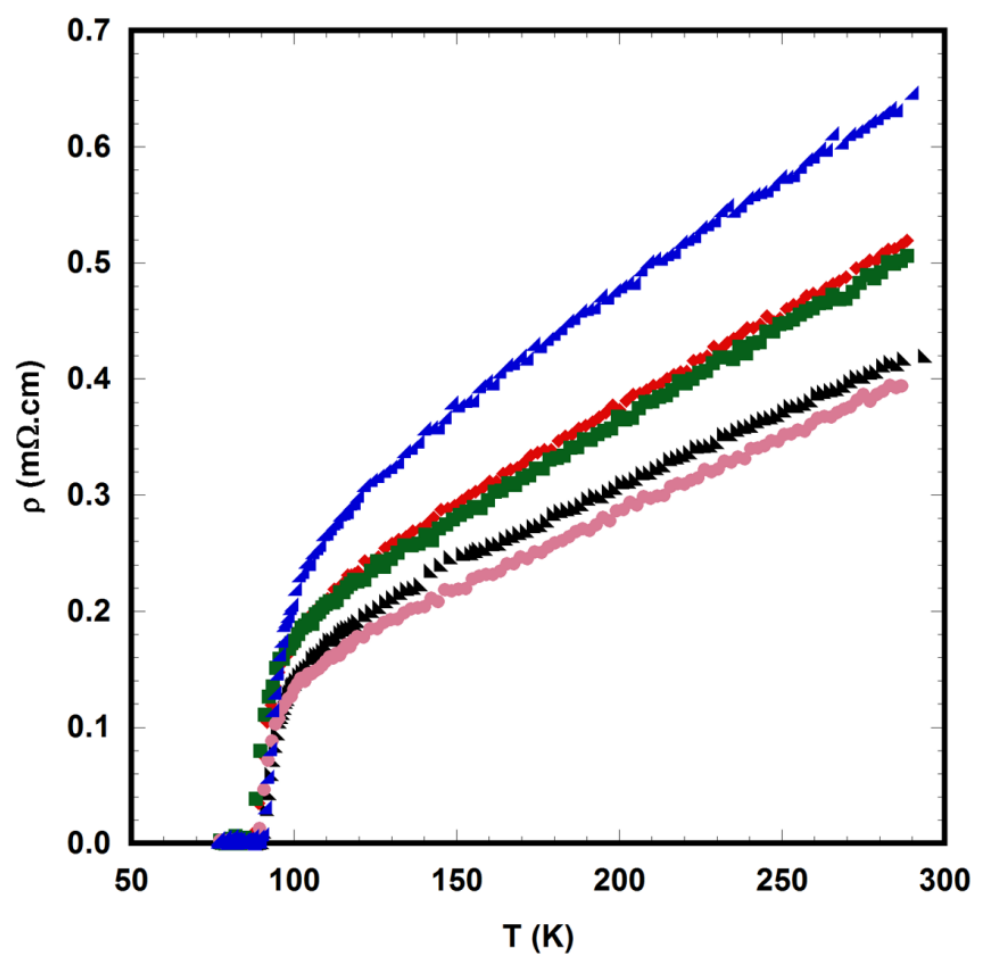


Figure 4
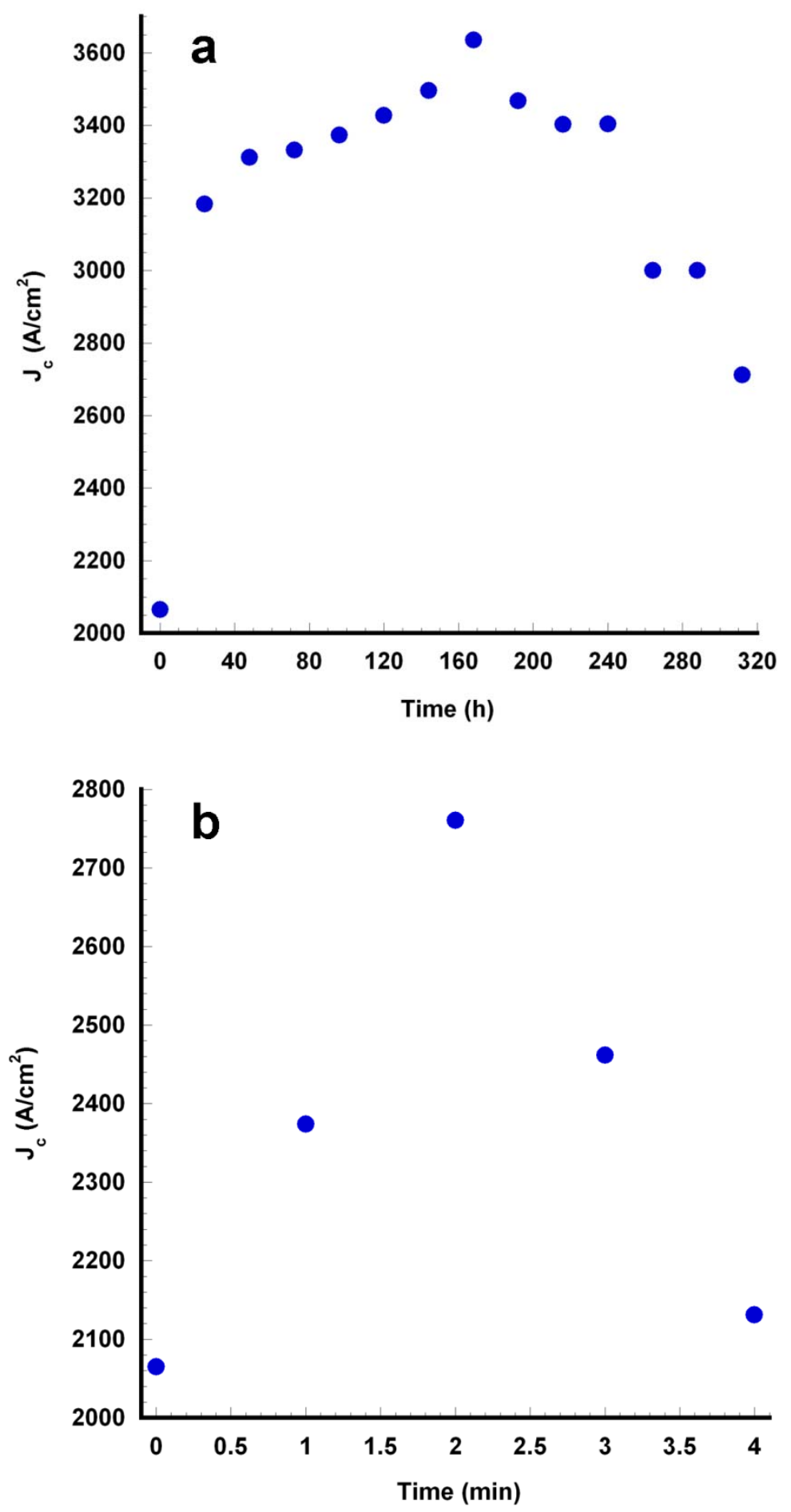
Figure 5
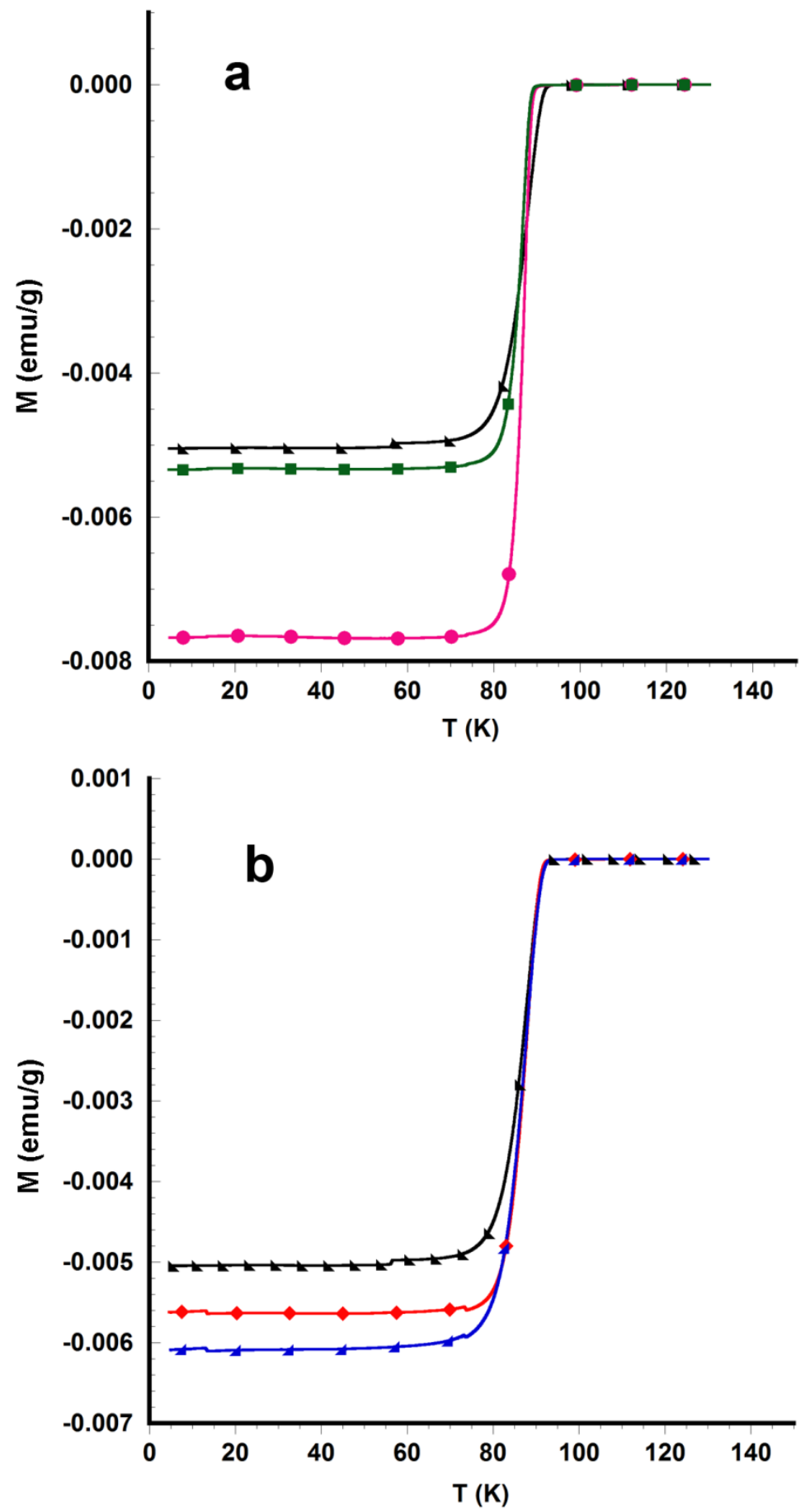
Figure 6
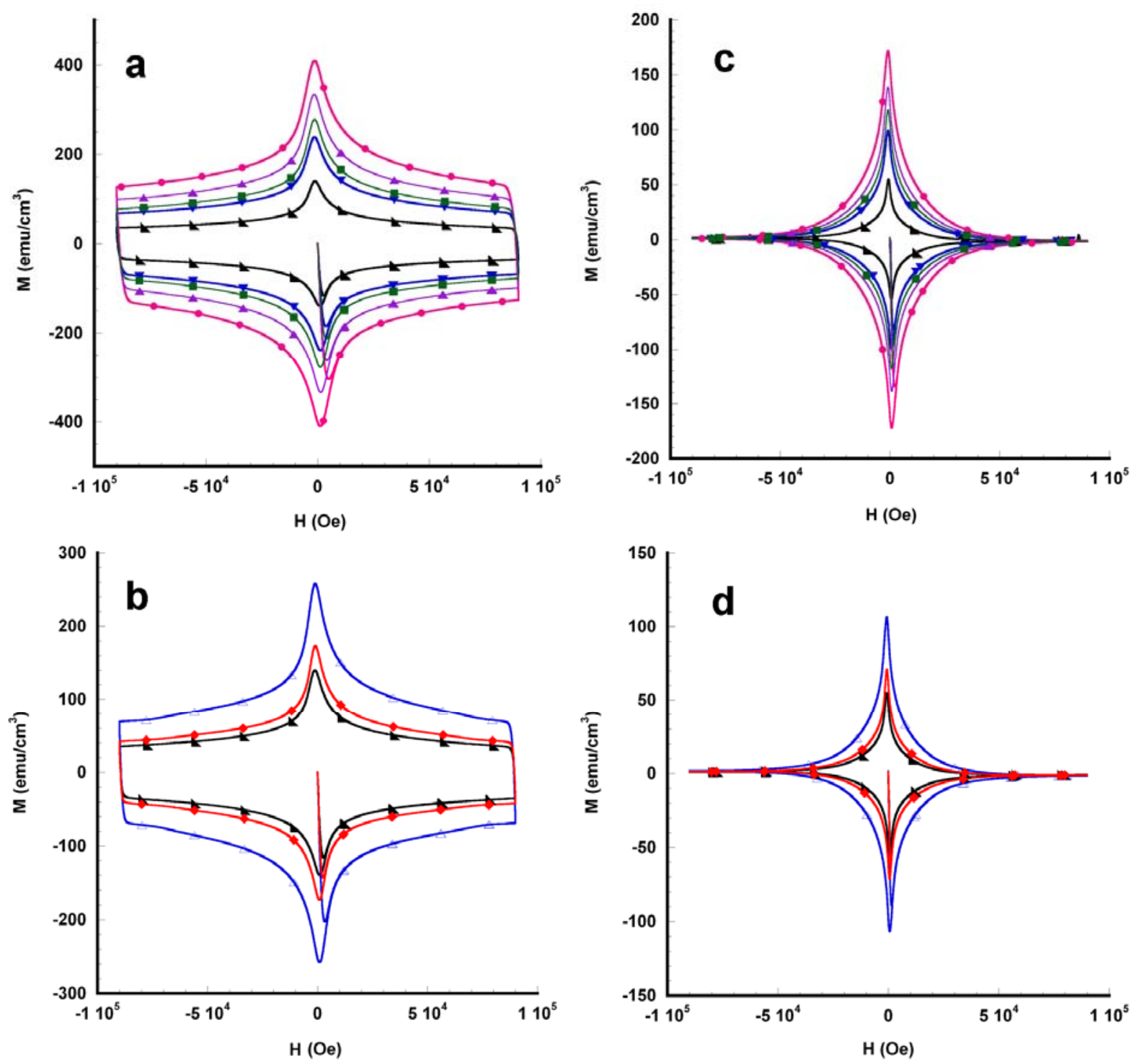
Figure 7
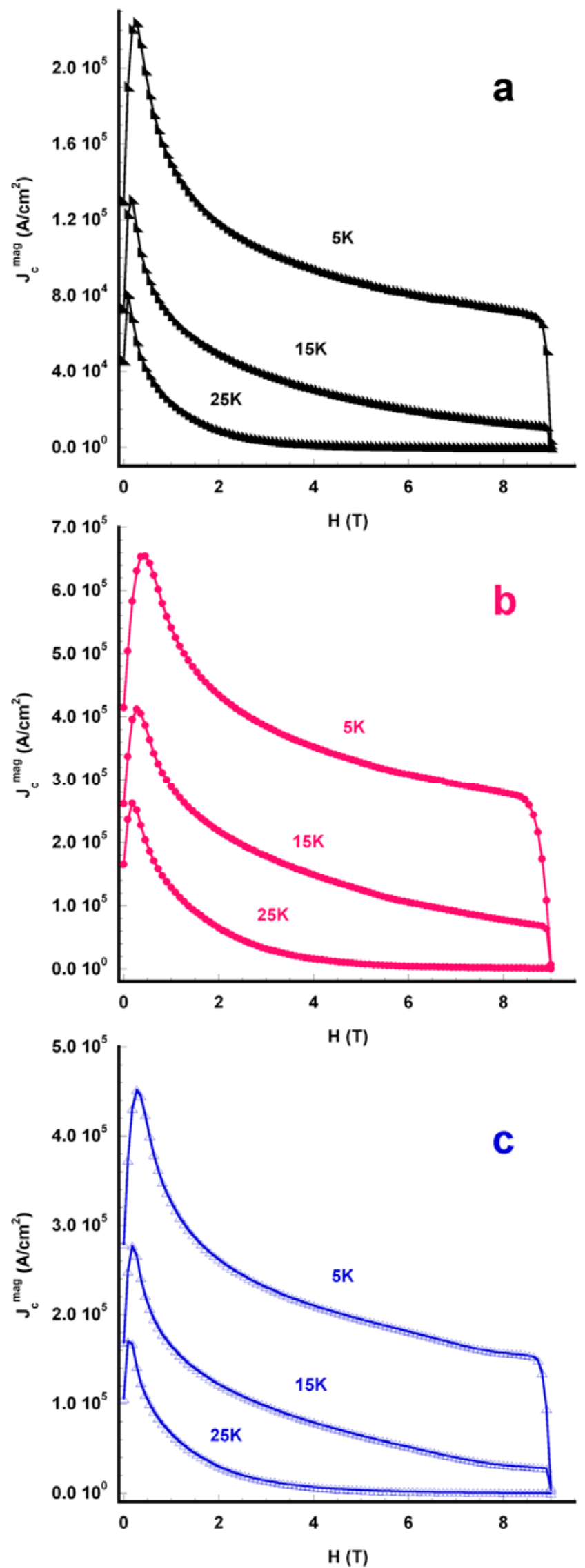